Témoigner Témoigner. Entre histoire et mémoire

Getuigen Revue pluridisciplinaire de la Fondation Auschwitz

$118 \mid 2014$

Au nom des victimes. Dictature et terreur d'État en Argentine, Chili et Uruguay

\title{
De plaats van het slachtoffer: landschap en rouwproces
}

La place de la victime: deuil et paysage

Sites of victimhood: mourning and the landscape

Jens Andermann

Traducteur : Antonia García Castro

\section{(2) OpenEdition}

Journals

Édition électronique

URL : http://journals.openedition.org/temoigner/1107

DOI : 10.4000/temoigner. 1107

ISSN : 2506-6390

Éditeur :

Éditions du Centre d'études et de documentation Mémoire d'Auschwitz, Éditions Kimé

Édition imprimée

Date de publication : 1 octobre 2014

Pagination : 127-134

ISBN : 978-2-84174-674-3

ISSN : 2031-4183

Référence électronique

Jens Andermann, «De plaats van het slachtoffer: landschap en rouwproces », Témoigner. Entre histoire et mémoire [Online], 118 | 2014, Online op 01 octobre 2015, geraadpleegd op 23 octobre 2020. URL : http://journals.openedition.org/temoigner/1107 ; DOI : https://doi.org/10.4000/temoigner.1107 
ARGENTINIË, URUGUAY, CHILI

\section{De plaats van het slachtoffer: landschap en rouwproces}

$\rightarrow$ Jens Anderman Universiteit van Züric
(1) Vgl. Pilar Calveiro, Poder concentracion en Argentina,
cons de Buenos Aires: Colihue, 1998
en Claudio Martyniuk, ESMA Fenomenología de la desaparicicion.
Buenos Aires: Prometeo, 2004 . (2) Jan Assmann, Das kulturelle und politische Identität in frühe Hochkulturen [1992], Mün
C. H. Beck, 2007, 60-63.

(3) Robert Pogue Harrison, The Dominion of the Dead, Chicaga:
University of Chicago Press, 2003, 20-21.

(4) Vgl. Alejandro Kaufman, 'Los la crisis' in Id. La pregunta por to acontecido: Ensayos de anamn en el presente argentine, Lan

(5) Jean-Luc Nancy, Au fond

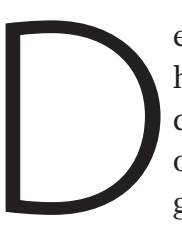

gruwel van de Latijns-Amerikanse dictaturen beperkt zich niet tot het systematische karakter van de militaire acties. Naast het aanhou-
dende geweld 'verdwenen' ook nog eens de lichamen van de slachtdende geweld 'verdwenen' ook nog eens de lichamen van de slachtoffers. Die verdwijningen vormden een essentieel onderdeel van het gevangenissysteem en dienden maar één doel: het verbreken van he de transitie geblokkeerd van communicatieve nan er niet worden gerouwd individuele dagelijkse emotie naar gemeenschappelijk verhaal ${ }^{2}$ Sinds de oudheid wordt het licham van de overledene begraven om een plats te kunnen wijde

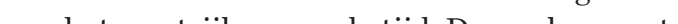

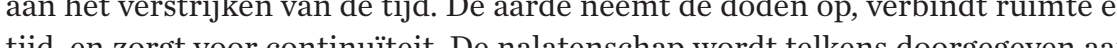
tijd, en zorgt voor continteit. De nalatenschap wort telkens doorgegeven aa de volgende generatie. We dragen zorg voor een gemeenschappelijke plek, die een oevluchtsoord wordt in het rouwproces.

Met de verdwijning van de lichamen heeft het dictatoriale regime moedwillig een breuk veroorzaakt in het begrafenispact ${ }^{3}$, dat is verankerd in de materiële en symbolische band tussen de aarde en het stoffelijk overschot. In het licht van de misdaden van de militaire dictaturen in Latijns-Amerika spreekt men vaak van een 'representatiecrisis'. Misschien verwijst die term niet zozeer naar het onmeetbare of onuitspreekbare geweld dat systematisch werd gepleegd op de lichamen van de slachtoffers ${ }^{4}$, mar veeteer nar het systematische gebrek ap de lichan een par rouwen. Zoworden niet alle no de goed verdreven van de gemeenschappelijke vaderlandse grond. Net mat het zo moeilijk is om persoonlijk verdriet voor een afwezig lichaam een plaats te geven in het continuth van vaderlandse tijd en ruinte, wordt in de kunsten en tijden herdenkingsplechtigheden bijzonder veel aandacht besteed aan het landschap, dat tegelijk de representatiecrisis symboliseert en er een oplossing voor biedt.

In de Westerse schilderkunst en literatuur drukt het landschap de ruimtelijke crisis uit in de moderne tijd: het is een symptoom, maar ook een remedie tegen de ontworteling die de mens ervaart als de aarde onroerend goed wordt. Terwijl het land er vroeger was voor de landbouwer, zo suggereert Jean-Luc Nancy, ontstat in het quattrocento een landschap dat zich opent voor het onbekende. Een afwezigheid nestelt zich in de zigheid 
ARGENTINIË, De plaats van het
slachtoffer: landschap en rouwproces het landschap in de herinnering precies de grote leegte gaan vullen die is ontstaan door de verdwijning van de lichamen: het landschap symboliseert niet meteen de slachtoffers, maar geeft op een ruimtelijke manier betekenis aan de lege plaats in de rouwende familieleden.

In dit artikel bestudeer ik de complexe en paradoxale rol van het landschap als plaats van het slachtoffer. Ik concentreer me op twee registers van post-dictatoriale herinnering in Argentinië, Uruguay en Chili, namelijk de herinneringsparken die in de jaren negentig werden aangelegd en de films van de kinderen van verdwenen personen die na 2000 zijn verschenen.

\section{GEBROKEN TUINEN}

De herinneringsparken in de Zuidkegel bouwen voort op een rijke traditie waarbij de herinnering van de overwonnenen (indianen, landbouwers, arbeiders) word toevertrouwd aan de mnemonische kracht van het landschap. Dat betekent dat er ook een vaste plaats wordt gegeven aan de onherstelbare breuk die het dictatoriale geweld veroorzaakte in het maatschappelijke weefsel. Zulke projecten gaan uit van de therapeutische kracht van de organische vormen van de landschapsoëtica-de

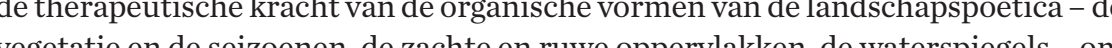
vegetatie en de seizoenen, de zachte en ruwe oppervlakken, de waterspiegels - om Toch bestaat toch nog altijd het gevaar dat het verleden wordt vergeten, omdat de natuur los staat van de ervaring en de pijn van toen. Daarom is een monumentale interventie nodig om het organische ritme te verstoren en het historische drama in te schrijven in het landschap. James Young betoogt in zijn studie over de Holocaus dat het monument spanning creëert in de ruimte waar het zich bevindt: door het landschap ‘uit te dagen' moet het vermijden dat de herinnering erodeert en 'oplost in het landschap en de vergetelheid' ${ }^{6}$

De herinneringstuin ensceneert het drama bij elk bezoek. De natuurlijke vormen wekken bij de bezoeker de hoop op heling na het gewelddadige verleden, maar die illusie wordt doorprikt door de monumentale interventie en de dwingende vraag naar herinnering. De hedendaagse herinneringsparken doorbreken het fragiele evenwicht tussen natuur en cultuur met historisch geweld, en stellen zo het teleologische interpretatieschema in vraag. Dat is precies wat er gebeurt in het Villa Grimaldi Vredespark, dat in 1997 werd ontworpen op de verlaten terreinen van één esthetisch principe bestaat er dan wel in om de ruwe en hobbelige oppervlakken van het verleden glad te maken, toch zien we overal subtiele tekenen die wijzen op onuitgesproken contradicties: we willen immers schoonheid brengen op plekken van immense gruwel, ${ }^{, 7}$

De grondstructuur van het park is een kruising van paden in de vorm van een $\mathrm{X}$, waarin we het religieuze symbool van het kruis herkennen en dus de verwijzing naar de nationale gemeenschap. Het is een gapende leegte en een toevluchtsoord voor van daaruit een ruimte te creëren die niet kan worden aangetast door terreur of traumatische amnesie, een soort van open plek in de stedelijke en nationale structuur. van de grootste clandestiene gevangenis- en foltercentra van Santiago de Chili. 'Het

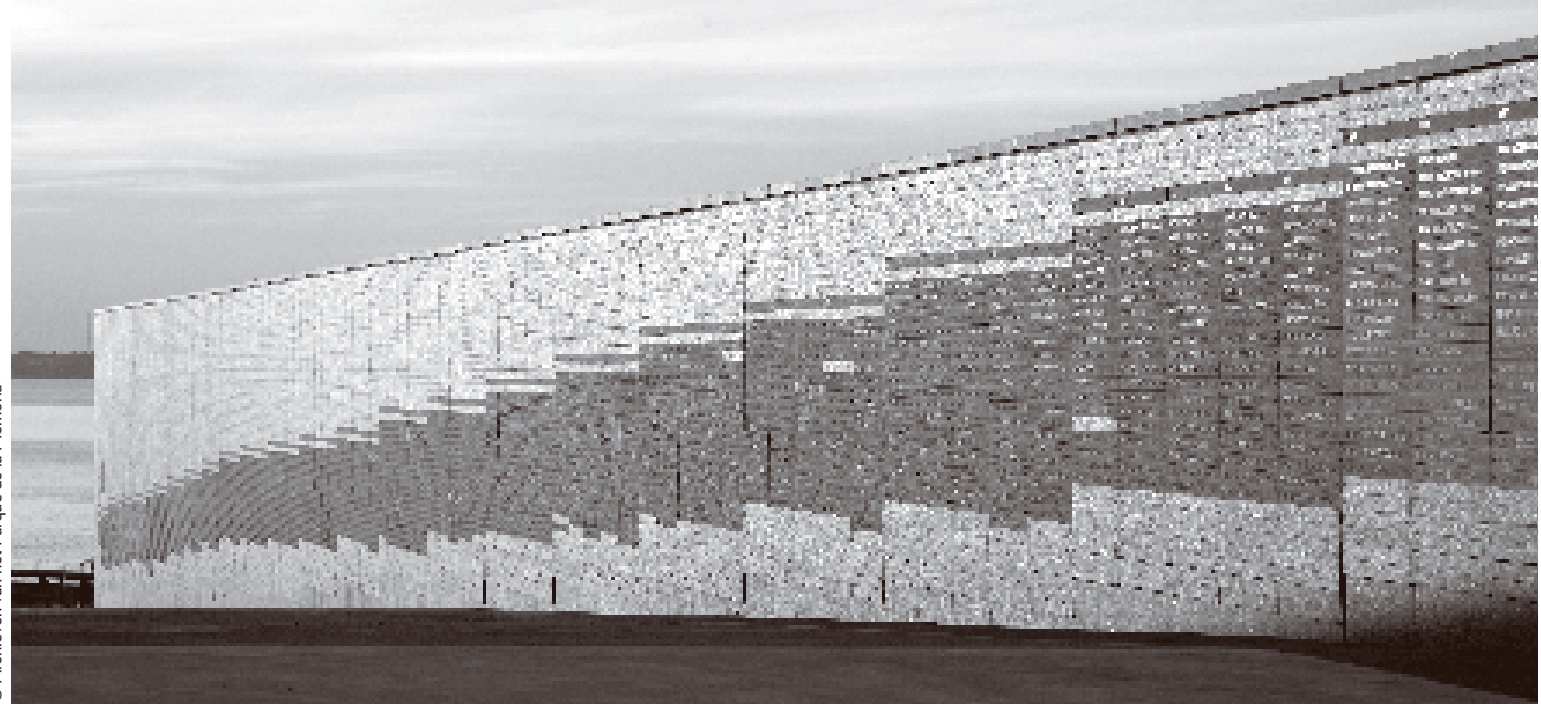

een grafsteen, maar ook het teken 'No+' dat het verzet in Chili gebruikte toen dat het een grafsteen, $\mathrm{m}$ (de wandelpaden ligt de 'Patio Deseado', een cirkelvormige plek met een fontein, bestaande uit een mozaïek van brokstukken afkomstig van het verwoeste clandestiene kamp. De Patio is begroeid met kleurrijke planten en een grote variëteit aan bloemen, waardoor de allegorische betekenis van de fontein duidelijk wordt: net als het park zelf symboliseert de fontein puurheid en hergeboorte, de doop van een gemeenschap die de confrontatie moet aangaan met de donkerste bladzijden uit haar geschiedenis.

De harmonieuze geometrie van de verlossingssymboliek wordt echter doorbrocentrum te zien, met name de cementen muren met prikkeldrad en hetvormalige (a) zwe badva he Der geheime politie. De overblijfselen van de gruwel zorgen voor een temporele kloof met de locus amoenus van de tuin: het vuile en troebele water in het verlaten zwembad staat in schril contrast met het zuivere, heldere water van de centrale fontein. Nog andere elementen uit de Villa werden 'gerecupereerd', zoals de mozaïekstukjes op de panelen die de verschillende etappes aangeven in de lijdensweg van de gevangenen. De panelen bestaan uit resten van de afbraak en geven telkens plaatsen aan die vandaag niet meer bestaan. Kritische waarnemers toonden zich ontevreden over 'de namen die weliswaar mooi in elkaar zijn gepast en harmonieus samenvloeien in de mozaïek mar die ons niet vertellen hoe de hele wereld van de slachtoffers afbrok kelde, tot zij enkel nog stamelend en bevend hun ontwrichting konden verwoorden, Mar to ten ${ }^{8}$. Maar misschien drukt de 'schoonheid" van de vormen en de kleuren net de afwijzing uit van elke documentaire of reconstructieve benadering. De panelen verwijzen
- Monument voor de slachtoffers van de een plaats kreeg in het Buenos Aires (Argentinië) aan de oever van de Rio ken door de rünes van de Villa Grimaldi. Daar zijn nog delen van het clandestiene herinneringspark van 
ARGENTINIË, De plaats van het en rouwproces
(vervolg)

(9) De uitdrukking is van Matía Almeida, in wiens gezelschap it

(10) Macarena Gómez-Barris, Where Memory Dwells: Culture Berkeley: University of California Press, 2009, 70 .

(11) Perdo Alejandro Matta, een overlevende van de Villa
Gimaldi, schreef een gids voor Grimaldi, Santiago de Chile: A vitgegeven in eignen beho $\mathrm{C}$ uitgegeven in eigen beheer,
2000 . Ik verwwijs ook naar Micka

J. Lazzara, 'Tres recorridos

- Memoriaal voor de gevangen en verdwene Ferreira van Met Park Vaz Ferreira vave
(Uruguay)

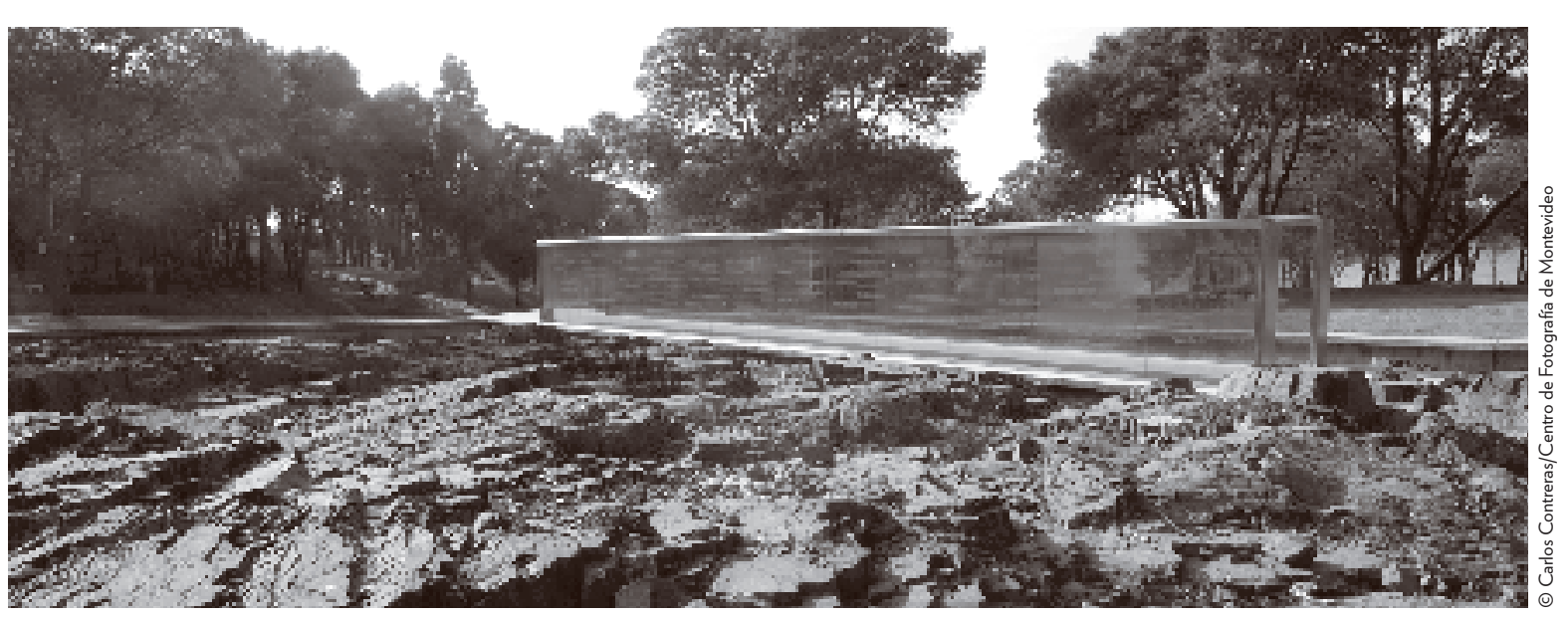

gevallen is de tuin niet bedoeld om de ruimte te 'recupereren', maar verbeeldt die de herinnering op een allegorische manier als gedeelde ervaring. De tuinen werden bewust 'aan de rand' aangelegd, op elk van de oevers van het water dat zo'n bijzondere betekenis heeft voor de 'cognitieve kaart' van de stad.

Net als in het Park Villa Grimaldi wordt de eenheid van ruimte doorbroken door twee tekstvormen die de afwezigheid moeten verwoorden. Op beide monumenten zijn namen gegraveerd op gladde oppervlakken: het zijn de namen van de slachtoffers van de terreur die vandagg gekend zijn, met hier en daar lege plekken war namen van de ter war namen toegevoegd kunnen worden. Martha Kohen en Rubén Otero installeerden voor hun project in Montevideo tweepan de heuvel. Het Memoriaal vanAlberto Varas in Buenos Aires is daarentegen opgebouwd uit een zigzagstructuur van porfieren muren, die voor de helft ingewerkt is in de heuvel die de ingang van het park en de sculpturengalerij ${ }^{12}$ afscheidt van de rivier.

In beide parken worden de locatie en het landschap op een verschillende manier gemarkeerd en uitgedaagd in hun ruimtelijkheid. Kohen en Otero bouwden hun monument op een 'open plek in een bos' die 'rustiek' oogt en een eind afligt van de rest van het park. De bezoeker moet een lastige zoektocht ondernemen, om via kronkelpaadjes uiteindelijk uit te komen bij de 'schrale waarheid' die ligt verscholen p de plek. Daar stan de namen vande afwezigen, terwijl de blote rots de blik naar (n) de bossen in de verte leidt. Het spel van licht en schaduw tussen het bos en de open plek zorgt voor een geografische projectie, een soort overlapping van twee beelden. Doordat de namen in reliëf het licht weerkaatsen, vormt het heldere glas 's nachts een baken hoog in de lucht. ${ }^{13}$

Het monument van Varas doorkruist dan weer op grondniveau de gebogen lijnen van het park als een kwetsuur, of een bliksemschicht. Om de ervaring van ontworteling en desoriëntatie uit te beelden, belemmert het monument het zicht en de beweging van de bezoekers, en dwingt het hen om langszij langzaam af te dalen. Dankzij de geforceerde route lezen we de ruimte op een specifieke manier. Het monument bevat de namen van de afwezigen en vormt een overganosplek tussen de stad war zij heblen gelefd en gestreden, en het water war zij wa zij waarschijnlijk de dood hebben gevonden.

In plaats van zich 'in het landschap in te nestelen', dagen de twee monumenten de ruimte uit. Ze doorbreken de ruimtelijke continuïteit, en symboliseren de onmogelijke verzoening tussen de historische teleologie van de overgangsverhalen en de gebroken en gefragmenteerde tijdsbeleving sinds de staatsterreur. ${ }^{14}$

\section{DOELLOZE LANDSCHAPPEN}

De afgelopen vijftien jaar kwam het thema van het dictatoriale verleden en de revolutionaire strijd van de jaren zeventig regelmatig an bod in films van de zogenoemde 'Nieuwe Argentijnse Cinema'. Marí Inés Roqué (Papá Ivín, 2000) Andrés Habegger ( $(H)$ Historias cotidianas, 2000) stellen in hun werk de kracht van
(12) De sculpturen werden uitgekozen door een
internationale jury nadat het project van Varas werd Varas zelf en zijn team van
landschapsarchitecten hebben geen inspraak gehad in die "El arte en los limites de divestri. representación', Punto de Vista

(13) 'Memorial de los Detenidos arquitectura y diseñode, Tran Ecuador 82, 2003, http: //ww trama.com.ec/espanol/revistas/ articuloCompleto. php? ?dRevista
6\&numeroRevista $=82$ \&articulold $2=64$ (gerradpleeg

maart 2011)

(14) James E. Young, The Texture
of Memory, op. cit., 14. 
ARGENTINIË, De plaats van het
slachtoffer: landschap en rouwproces
(vervolg)

(15) Ana Amado, La imagen justa: cine argentino y política (1980-
2007), Buenos Aires: Colihue 2007), Bues, 165 .

(16) Gonzalo Aguilar, Otros cine argentino, Buenos Aires:
Santiago Arcos, 2006, 41 .

(17) Christian Gundermann,
Actos melancólicos: Formas de

Actos melancolicoss: Formas

argentina, Rosario: Bea
Viterbo, 2007, 25.

(18) Roland Barthes, La chambre

claire: Note sur la photographie, Laura Mulvey, Death $24 \times$ Second Stillness and the Moving I mage

(19) De film Los rubios

(Argentinie, 2003) werd

Carri. De cineaste vertelt over
de verdwinining van haar ouders

de verdwijning van haar ouders

en over het clandestiene leven
van het gezin in de periode die

hieraan voorafging. In een $n$

van documentaire en fictie,
realiteit en herinnering, schept ze
bruggen tussen verleden, heden

bruggen tussen ver
en toekomst. Nvdr. de getuigenis in vraag. Kunnen getuigenissen weerstand bieden tegen terreur, en maatschappelijke banden herstellen? De films zijn gemaakt vanuit het perspectie van een generatie die één of beide ouders heeft verloren, en dus een emotioneel en historisch gemis ervaart. De helingskracht van de getuigenis wordt voortdurend uitgespeeld tegen haar onmacht om een leven vorm te geven dat is gebouwd op een leegte - de kinderen kennen hun afkomst niet -, en tegen haar onvermogen om die leegte op te vullen met historische 'kennis'. Niet alleen kan men die kennis onmogelijk reconste ve eur gevallen nekend. In een 'formee anachronistisch spel ${ }^{15}$ met de afwezige ander, die voortdurend de aandacht opeist, tonen de cineasten ons hun doelloos en aarzelend werk van herinnering, hun pogin om een eigen plaats te vinden en zich te situeren tegenover de vorige generatie. Roqué vertelt in Papá Iván: 'wat ik het meest heb gemist is zijn blik. De blik van je ouders is er een van bevestiging, hij vormt je, maakt je tot wat je bent. En dat is een beetje... dat is zoals opgroeien op de tast'.

In de film wordt de uitspraak kracht bijgezet door een reeks panoramische zwart-witbeelden van boomtoppen en weilanden. De beelden zijn gedraaid vanuit de trein of de auto: ze zijn wazio ze flitsen voorbij, en verwijzen naar de frustratie van de herinnering De weergave van de reis in een bewegend shot, als allegorie van de (e) van de deel uit van de visele gamnatica in het wek vandschap heefthierechterniet alleen eenretorschefunctie. Deruimtelijke beweging is ook de concrete uitwerking van het rouwproces waarbij de kinderen getuigen en plaatsen ui het verleden opzoeken, sporen vastleggen en de impact ervan meten op het heden. Omdat de films een oprechte interesse tonen in de verhalen van vandaag, zijn het voorbeelden van wat Gonzalo Aguilara de "nomadische tendens ${ }^{96}$ noemt in de nieuwe Argentijnse cinema. De tegenwoordigheid van het heden is echter onbestendig: een scène uit de film $(H)$ Historias cotidianas toont een jonge journaliste die vandaag ergens in een stad de plekken uit haar jeuod probeert terug te vinden aan de hand van een foto die is genomen voor de verdwijning van har ouders. De foto foto van het gezin en het lichaam van de volwassen vrouw vormen samen een 'melancholische scène ${ }^{47}$, een tafereel waarvan de intieme en politieke betekenis wordt onderstreep door de verwantschap (gelijkenis en tegelijkertijd verschil) tussen de twee media, fotografie en film. De filmmaker stelt de beweeglijke camera tegenover de statisch foto uit het familiearchief, om te benadrukken dat het herinneringswerk een zaak is tussen twee generaties. De tijd staat stil op het fotografische beeld, en vormt met het bewegende filmshot een voornamelijk ruimtelijk contrast, waarbij het verschi opvalt tussen de monumentale plek enerzijds en de bewegenderuimte van het doelloze rouwproces anderzijds.

In Los rubios ${ }^{19}$ toont Albertina Carri beelden van de 'campito', het platteland rond Buenos Aires waar zij met haar zussen werd heengebracht na de ontvoering van hun ouders - een plaats met een grote emotionele waarde dus. Volgens Joanna Page vorm het rurale element in Los rubios een ruimte voor cinematografisch experiment en vriendschap binnen de filmploeg. Die ruimte staat in schril contrast met de voorsteden van Buenos Aires, waar Albertina's ouders Roberto Carri en Ana María Caruso werden ontvoerd, en die het decor vormen van een emotioneel afmattende zoektocht. ${ }^{20}$ Tegelijkertijd belicht de film enkele lugubere aspecten van de schuilplaats van de kinderen. De dubbelzinnige betekenis van de plek blijkt al uit de benaming: het Spaanse 'campo' betekent zowel terrein, platteland, als kamp, en verwijstzonar die 'andere plek' die de schuilplats moest doen vergeten. wijst zona de cho Ondanks de trasschen werk deze plek van kinderlijke vrijheid herwinnen. Het wordt een ruimte voor improvisatie en (zelf)constructie, een ruimte die ze kan en wil delen om nieuwe emotionele en politieke banden te creëren. De 'campito' is een ruimtelijke afbeelding van het radicale project van de film zelf: het is een plaats voor de enscenering van de intense en tegengestelde emoties die de afwezigheid van de ouders oproept. Dat gemis is zichtbaar in de uithoeken en de verborgen plekjes van de 'rurale natuur'. De 'campito' is ook een open terrein voor de constructie van individuele en collectieve identiteiten die dynamisch en voortdurend in beweging zijn. Aan het einde van de film is bijvoorvoortd ilm ber beeld de filmploeg aan het werk oneen scène voor te bereiden - Los rubios maakt veelvuldiggebruik van het procedé waarbij het cinema-

tografisch werk zelf wordt gefilmd, en het beeld dus op een reflexieve manier wor verdubbeld. Terwijl de cameramensen en geluidstechnici verschillende hoeken en posities uitproberen, geeft regisseur Albertina Carri aanwijzingen aan actrice Analía Couceyro, die in het volgende deel van de film Carri's personage zal vertolken. De rollen - regisseur, acteur, camera - zijn niet strikt verdeeld en blijken zelfs inwisselbaar Het fluctuerende aspect van het filmwerk vinden we ook terug in het tijds- en ruimtekader van de shots in deze specifieke scène. Het segment wordt immers onderbroken door korte close-ups van de natuur - een kolonne mieren, onkruid en bladeen - en eindigt met twe doorlopende shots: en trage panoramaopname vanlinks ren - en eindigt net naar rechts ter hoogte van de bomen aan de horizon, met Carri in voice-over die haar ploeg vertelt wat ze van de geluidsopname verwacht; daarna een panoramaopname waarbij een handcamera rond Albertina en Analía cirkelt terwijl ze samen de toon bespreken van de tekst voor de volgende scène.

We zien de actrice in beide shots, waardoor het onderscheid tussen 'documentaire realiteit' en 'fictie' opnieuw vervaagt. Ze spreekt 'over Albertina. Ze spreekt in de eerste persoon'. De twee vrouwen voeren een technisch gesprek en zoeken uit of ze de eerste persoon kunnen vermijden door het gebruik van passiefconstructies ('ze werden datzelfde jaar nog vermoord'). De hele scène, zo kunnen we wel stelen draait om het vraagstukvan de persoonlijkheid. Doordat de shots zijn gemaakt vanuit onbepalde mmaticaal - en dat de blik van de kijker via een lineair perspectief door een overzichtelijke
(20) Joanna Page, 'Memory
and Mediation in Los rubios: A Contemporary Perspective of the Argentine Dictctorship,
New Cinemas $3(1)$. 2005, 31: 
ARGENTINIË, De plaats van het
slachtoffer: landschap en rouwproces
(vervolg)

(21) Karel Reisz \& Gavin Milla New York: Hastings, 1968, 216, Stephen Heath, Questions of University Press, 1981, 19-75. (22) Gilles Deleuze, Cinén Minuit, 1983, 155.

(23) Nelly Richard, 'Sitios de recuerdo', op. cit., 12 .

(24) Marcelo Brodsky, Nexo,
Buenos Aires: La Marca, 2008,

ruimte leidt, wordt hier radicaal omgegooid met circulaire panorama-opnames die de 'regel van 180 graden ${ }^{21}$ overtreden. Door de verwarring over persoonlijke voornaamwoorden en het wisselende camerastandpunt krijgt de persoonlijke ervaring een intersubjectieve dimensie, en wordt de ruimte van het subject een terrein voor experiment - een willekeurige ruimte, om Deleuzes term te gebruiken, 'een ruimte voor virtuele ontmoetingen, een zuivere plek van potentialiteit. ${ }^{22}$

Het hele project van Los rubios valt misschien wel samen te vatten in een poging om het vraagstuk van de persoonlijkheid - die van Albertina maar ook die van har om het afwezige ouders en hun strijdgenoten - over te hevelen naar een 'Willekeurige ruimte, waar relaties en enoties het object kunnen won wan wat Deleuze een 'akte van geloof noent. een emotionele en politieke onkering, gericht op een toekomst die nog volledig open ligt. Die transformatie van monumentale plaats naar 'willekeurige ruimte' is misschien wel dat wat de architectonische en cinematografische werken met elkaar gemeen hebben: ze wissen de sporen van de monumentale inschrijving niet uit, maar gebruiken ze als basis om een radicaal performatief project uit te werken. Hoewel in Albertina's geval de 'willekeurige ruimte' specifiek en individueel (genealogisch) blijft, weet de filmmaakster via een politieke en esthetische interventie (een akte van geloof) haar persoonlijke verhaal open te breken, zodat er collectieve elementen kunnen binnensijpelen met een experimenteel en zodat er collectieve elem

Wat is nu de rol van het landschap in deze composities? Is het een monumentalisering van het rouwproces of staat het symbool voor de 'dwalende' en doelloze herinnering? In haar kritische commentaar op het Park Villa Grimaldi stelt Nelly Richard dat de tuinen en memorialen slechts conventionele retorische figuren zijn om 'de herinnering te temperen, totdat die oplost in de bezonken onverschilligheid en vergetelheid die zo kenmerkend is voor steden ${ }^{23}$. In dit artikel heb ik echter de reële impact willen bestuderen die de verbreking van het begrafenispact heeft gehad op de 'natuurlijke' vormen die in het landschap een gezamenlijke betekenis krijgen. Dat wederzijdse corrosieve effect, van de aarde op het teken en omgekeerd, vinden we terug in het foto-essay van $\mathrm{Car}$, wa wa te

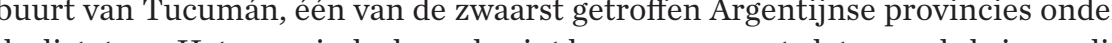
de dictatuur. Het organische leven begint haar sporen na te laten op de brieven die familieleden en vrienden van de verdwenen inwoners van Tucuman aan de bomen hebben geprikt. De letters worden onleesbaar, maar toch gaat de herinnering volgens Brodsky niet verloren, en is het niet zo dat 'degenen die men wil herdenken nu een tweede keer verdwijnen'24. Zijn foto's brengen iets in beeld dat treffende en complexer is, maar moeilijk in woorden te vatten omdat het woord zelf op het spel staat: het weet zich namelijk niet te hechten aan de natuur maar wordt erdoor verzwolgen. De foto's van Brodsky, met hun strakke en intieme kadrering doen on twijfelen moeten we hetverslinden van de woorden beschouwen alseen dad van agressie, of net van oneindige tederheid? 